\title{
Compression Test and Finite Element Analysis for Failure Criterion of the Tibial Post of a Posterior-Stabilized Knee Prosthesis
}

\author{
Rina Sakai1 $^{1}$, Urabe Ken ${ }^{2}$, Kazuhiro Yoshida' ${ }^{1}$ Kiyoshi Mabuchi' ${ }^{1}$ Masanobu Ujihira1 \\ ${ }^{1}$ Department of Biomedical Engineering and Technology, School of Allied Health Sciences, Kitasato University, \\ Sagamihara, Japan; ${ }^{2}$ Department of Orthopedic Surgery, Kitasato University Medical Center, Kitamoto, Japan
}

Correspondence to: R. Sakai, rinax@kitasato-u.ac.jp

Keywords: Proximal Humeral Fracture, Retrograde Intramedullary Nailing, Anterograde Intramedullary Nailing, Locking Plate, Internal Fixation

Received: April 15, 2019 Accepted: May 18, $2019 \quad$ Published: May 21, 2019

Copyright $\odot 2019$ by authors and Scientific Research Publishing Inc.

This work is licensed under the Creative Commons Attribution International License (CC BY 4.0).

http://creativecommons.org/licenses/by/4.0/

\section{(c) (i) Open Access}

\section{ABSTRACT}

Post cam mechanism of Posterior Stabilized (PS) knee prostheses is useful to realize intrinsic stability for cases with severe degeneration. However, some retrieval studies report severe failure of the polyethylene tibial post. We thought that severe failures were caused by high loads during daily activities. In the current study, we performed a compression test and a finite element analysis of the mechanical forces produced in the tibial post in posterior-stabilized knee prostheses in order to develop a specification for the tibial posts found in the polyethylene inserts of PS knee prostheses. Anterior tibial post impingement and posterior tibial post impingement were simulated. The surface pressure values detected in the compression test were consistent with those obtained in the FE analysis. Of the three designs, the lowest von Mises stress values were generated inside the round tibial post; therefore, tibial posts should be round. The risk of tibial post failure was low when 500 or $1000 \mathrm{~N}$ was loaded onto the knee joint. It was suggested that tibial post failure occurs when the shear strain at the base of the tibial post exceeds 0.1 .

\section{INTRODUCTION}

Posterior-Stabilized (PS) knee prostheses are equipped with a post-cam structure in which the polyethylene insert has a projection termed a post, which stabilizes the joint by joining with a cam of the femoral component. This structure realizes anteroposterior stability and physiological flexion as an alternate function of the posterior cruciate ligament after surgery, and favorable treatment outcomes were achieved. However, the occurrence of post breakage several years after surgery has often been reported [1-4]. Re- 
garding the cause, the procedure, such as abnormality of the angle set in surgery, has been discussed, but Chiu et al. reported a case in which placement failure was not confirmed but the post broke three years after surgery [5].

The cause of post breakage may be unexpectedly high stress loaded on the post. An index to design a safe post which does not break may be necessary, but there are no reports on this. Moreover, the amount and condition of weight-bearing which may cause breakage are also unclear. The post shape of commercially available PS-type knee prostheses varies among manufacturers. To identify a safe shape, it may be necessary to perform tests and numerical analysis of posts with different shapes under identical conditions and investigate an ideal shape based on the results.

In this study, posts of PS-type knee prostheses were subjected to a compression test and finite element analysis (FEA) on the assumption of mechanical conditions in the body to establish strength criteria for designing a shape.

\section{MATERIALS AND METHODS}

\subsection{Compression Tests}

PS-type knee prostheses, A, B, and C, were prepared (Figure 1). The characteristics of the post are different: small flat (A), small curved (B), and large flat shapes (C), respectively.

Pressure film (Prescale, Fujifilm, Japan) cut into an appropriate size was applied to the anterior or posterior surface of the post of the polyethylene insert of the three types. The compression test between the post and femoral component was performed (Figure 2). The maximum pressure $[\mathrm{MPa}]$ and pressurized area $\left[\mathrm{mm}^{2}\right]$ were determined using a pressure image analysis system (FPD8010J, Fujifilm, Japan).
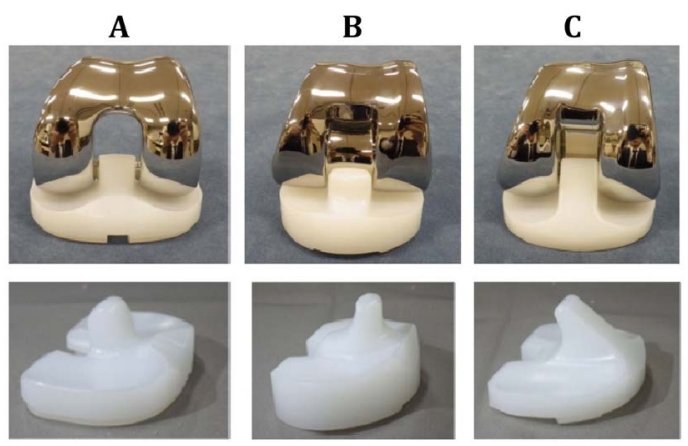

Figure 1. PS-type knee prostheses, A, B, and C.

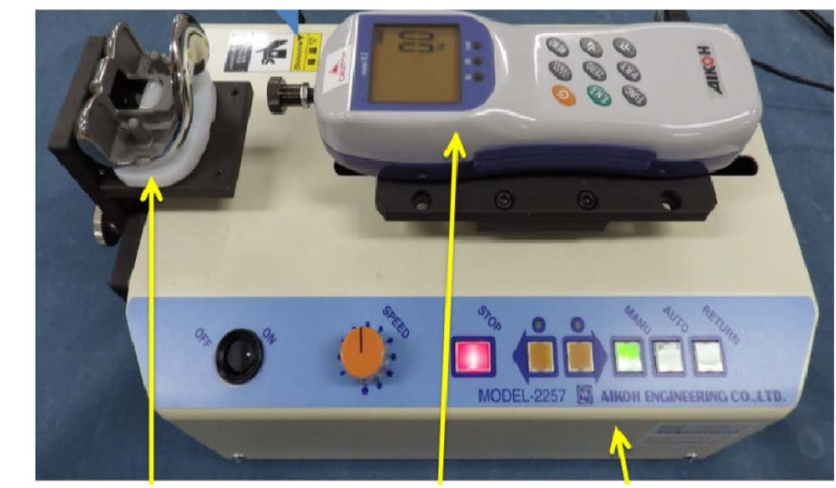

$$
\begin{gathered}
\text { Knee Prosthesis } \\
\text { (Polyethylene insert) }
\end{gathered} \text { Force Gauge Compression Tester }
$$

Figure 2. Compression tests. 
Measurement was performed at two flexion angles: $-10^{\circ}$ and $120^{\circ}$. It is known that the tibial surface internally rotates $5^{\circ}-10^{\circ}$ against the femur in deep flexion, measurement was also performed at $120^{\circ}$ flexion $+10^{\circ}$ internal rotation of the insert. The position at $-10^{\circ}$ flexion simulated overextension of the femur, reproducing impingement (collision) between the anterior surface of the post and femoral notch. The positions at $120^{\circ}$ flexion and $120^{\circ}$ flexion $+10^{\circ}$ internal rotation simulated deep flexion, reproducing impingement between the posterior surface of the post and femoral cam.

The femoral component and polyethylene insert were appropriately set, and forced displacement of a digital force gauge was applied at a speed of $20 \mathrm{~mm} / \mathrm{min}$ to load on the post. The load was applied taking about 10 seconds, and displacement was stopped when the force reached500 $\mathrm{N}$ and held for 5 seconds.

At $-10^{\circ}$ flexion, bone cement was molded and attached to the anterior region of the femoral component. At $120^{\circ}$ flexion, the epiphyseal region of the artificial femur (Femur with $11 \mathrm{~mm}$ Canal, \#1129-19, SAWBONES, USA) was cut in the anteroposterior direction, and the distal cross-sectional surface was covered with bone cement and attached to the femoral component. At $120^{\circ}$ flexion $+10^{\circ}$ internal rotation, bone cement molded in a triangular prism shape with a $10^{\circ}$ angle was placed between the anterior region of the polyethylene insert and the bottom plate of the tester to reproduce internal rotation of the tibial surface.

\subsection{Finite Element Analysis}

CT images of these knee prostheses were acquired, and DICOM data of each joint were collected. These data were read into image data processing software, using 3Dimage processing and preparation tool Scan IP (Simpleware, JSOL, Japan), and converted to STL data. The STL data of the femoral component and polyethylene insert were read-in using $+\mathrm{CAD}$ Module, and the positions and angle of the two parts were mutually adjusted so as to set the conditions identical to those of the measurements of the compression test. These data were re-read-in using Scan IP, and meshes were prepared using the automatic meshing function. Each element was constituted with a 4-node tetrahedron (Figure 3).

The prepared FE model was read-in using LS-prepost (TERRABYTE, Japan), and the material definition and boundary, contact, and weight-bearing conditions were set. In the material definition, the femoral component was prepared as a rigid model with a mass density of $8300 \mathrm{~kg} / \mathrm{m}^{3}$, elastic modulus of $210 \mathrm{GPa}$, and Poisson's ratio of 0.31 . For the polyethylene insert, a poly-linear approximation isotropic elasto-plastic solid model with a mass density of $935 \mathrm{~kg} / \mathrm{m}^{3}$, elastic modulus of $750 \mathrm{MPa}$, Poisson's ratio of 0.37 , and yield stress of $30 \mathrm{MPa}$ was prepared. Poly-linear was referred to in literatures and defined as a material [6].

For the boundary conditions, displacement against the femoral component in all axes excluding the $\mathrm{Y}$-axis and rotations in all axial directions were restricted, and the range of nodes on the bottom surface alone was specified against the polyethylene insert and completely restricted. For the contact, automatic contact was selected in consideration of slipping, and no gap element was used. The coefficients of static and mechanical frictions between the femoral component and polyethylene insert were set at 0.11 and 0.087 , respectively. The loading condition was defined so as to load a specific weight on the entire femoral component, which is a rigid model, in the Y-axis direction. The load to be applied was set at 500 and 1000 N.

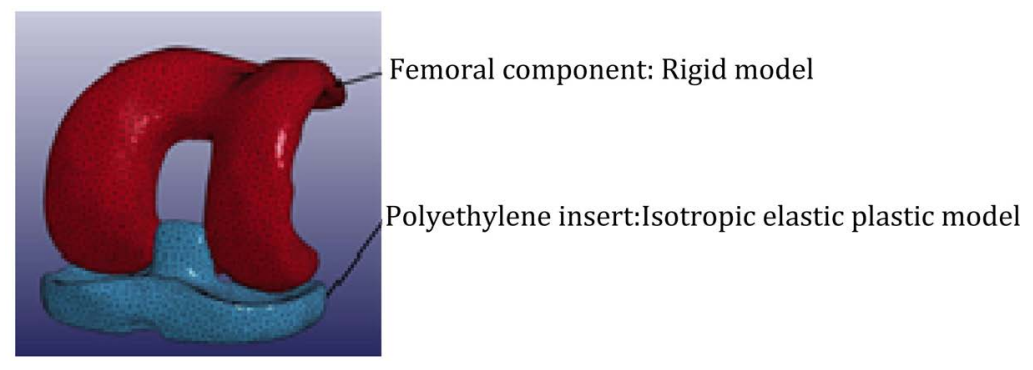

Figure 3. Finite element model. 
For the analytical system, LS-DYNA ver. 971 (TERRABYTE, Japan) and Endeavor Pro-4500 (EPSON, Japan) were used for software and hardware, respectively. The data was output every one second. For the analytical time, 10-second pressurization and 5-second retention, a total of 15 seconds, were set. The pressure generated on the post surface and Von Mises equivalent stress and shear strain generated in the post by loading were analyzed and output.

\section{RESULTS}

\subsection{Compression Tests}

At $-10^{\circ}$ flexion, the maximum pressures on the anterior surfaces of the posts of products $\mathrm{A}, \mathrm{B}$, and $\mathrm{C}$ were 49.8, 49.8, and 43.5 $\mathrm{MPa}$, respectively (Figure 4(a), top), and the pressurized areas were 16, 20, and $23 \mathrm{~mm}^{2}$, respectively.

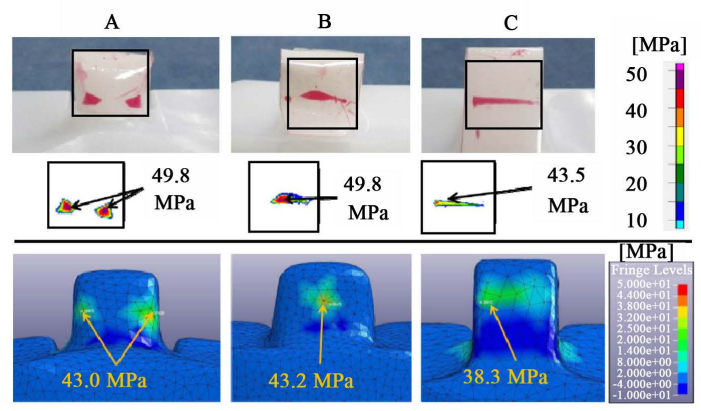

(a)

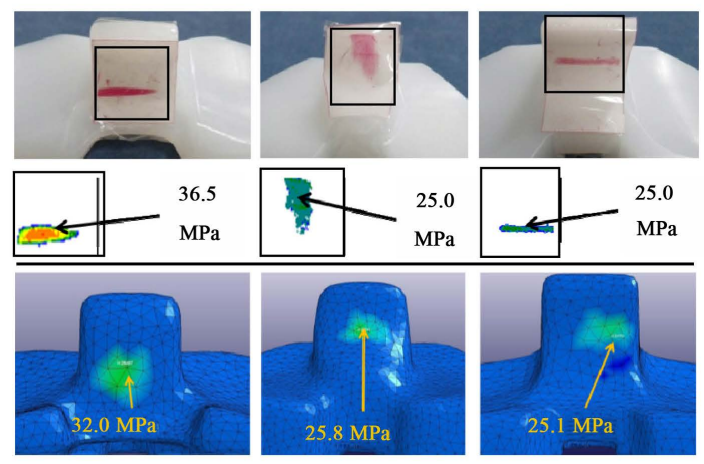

(b)
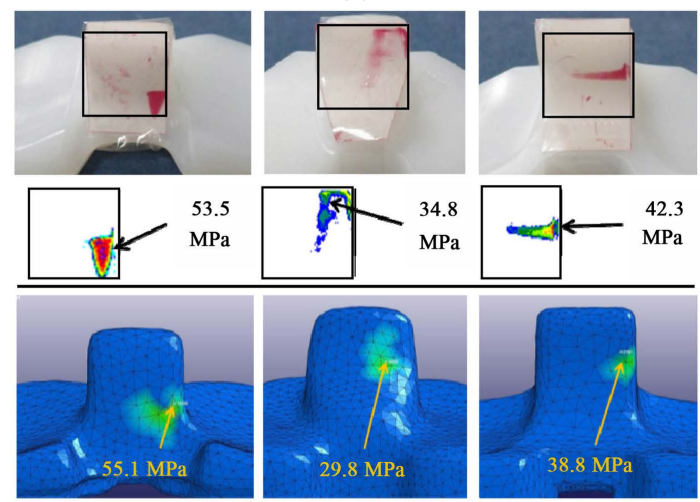

(c)

Figure 4. Surface pressure distribution. Top: Finite element analysis. Bottom: Pressure images were determined using analysis system. (a) $-10^{\circ}$ flexion; (b) $120^{\circ}$ flexion; (c) $120^{\circ}$ flexion $+10^{\circ}$ internal rotation. 
At $120^{\circ}$ flexion, the maximum pressures on the anterior surfaces of the posts were 36.5, 25.0, and 25.5 $\mathrm{MPa}$, respectively (Figure 4(b), top), and the pressurized areas were 18, 29, and $26 \mathrm{~mm}^{2}$, respectively.

The pressure distribution concentrated to the edge at $120^{\circ}$ flexion $+10^{\circ}$ internal rotation, compared with that at $120^{\circ}$ flexion. The maximum pressures on the posterior surfaces of the posts were $53.5,34.8$, and $42.3 \mathrm{MPa}$ (Figure 4(c), top), respectively, and the pressurized areas were 16, 33, and $23 \mathrm{~mm}^{2}$, respectively.

\subsection{Finite Element Analysis}

The maximum surface pressure and pressure distribution (Figure 4, bottom) loaded by $500 \mathrm{~N}$ on FEA were similar to the pressure distribution shown by the pressure film after the compression test, showing that the post-cam contact position was almost the same. The error from the maximum surface pressure on the compression test was within $15 \%$ in all products, showing that the values were consistent.

The maximum value of Von Mises-equivalent stress loaded by $500 \mathrm{~N}$ was lower than the defined yield stress $(30 \mathrm{MPa})$ under all measurement conditions in all products (Figure 5, Top). The stress level was relatively high at $-10^{\circ}$ flexion, whereas it was low at $120^{\circ}$ flexion. The addition of internal rotation of the insert to $120^{\circ}$ flexion increased stress on products A, B, and C by $24.2 \%, 6.8 \%$, and $23.3 \%$, respectively, showing that the rate of increase decreased in product $\mathrm{B}$.

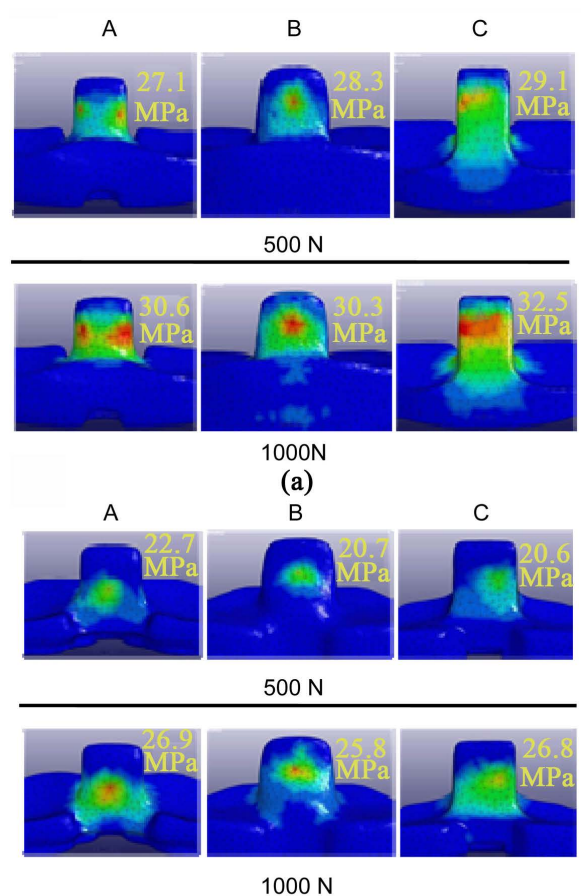

(b)

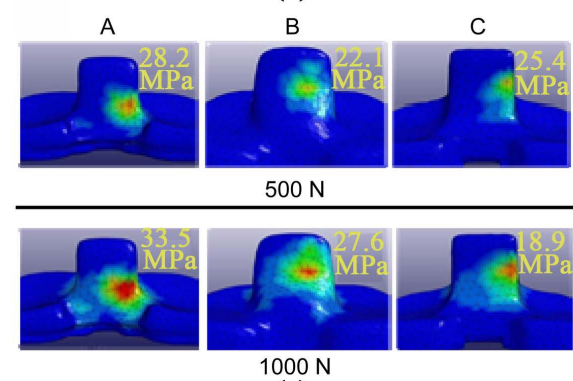

(c)

Figure 5. Von Mises-equivalent stress distribution. Top: 500 N. Bottom: 1000 N. (a) $-10^{\circ}$ flexion; (b) $120^{\circ}$ flexion; (c) $120^{\circ}$ flexion $+10^{\circ}$ internal rotation. 
When $1000 \mathrm{~N}$ was loaded, Von Mises-equivalent stress (Figure 5, Bottom) exceeding the defined yield stress $(30 \mathrm{MPa})$ was produced at $-10^{\circ}$ flexion in all three products and at $120^{\circ}$ flexion $+10^{\circ}$ internal rotation in product $\mathrm{A}$. The rates of increase due to internal rotation of the insert were $24.5 \%, 3.0 \%$, and $12.0 \%$ in products $\mathrm{A}, \mathrm{B}$, and $\mathrm{C}$, respectively, showing that the increase rate was relatively high in product $\mathrm{A}$ and low in product $\mathrm{B}$. The maximum value of $500 \mathrm{~N}$ load-induced shear strain was relatively high at $-10^{\circ}$ flexion in all three products, similar to Von Mises-equivalent stress. When $1000 \mathrm{~N}$ was loaded, shear strain exceeding 0.1 was produced at $-10^{\circ}$ flexion in all three products, and shear strain at $120^{\circ}$ flexion $+10^{\circ}$ internal rotation was much higher in product $\mathrm{A}$ than in the other products.

\section{DISCUSSION}

Small plastic deformation on the femorotibial joint surface may be acceptable in designing strength of a knee prosthesis (plastic design) because force acting on the femorotibial joint surface is compressive and even a large load causes plastic deformation, reduction of true stress by an increase in the contact area can be expected. However, in the post-cam structure, although the compressive force acts on the contact point of the post, tensile and bending forces may act on the root of the post. When plastic deformation occurs in the root, the area joining the polyethylene insert and post immediately decreases and true stress increases, which may break the post. In reports on post breakage, most posts removed from the body were broken at the root, showing that stress loaded on the root of the post is important to investigate in post breakage. It was suggested that to design a safe post, stress against assumed loads should be lower than tensile and bending strengths, and this should be set as a criterion. In consideration of this, the yield stress of ultra-high-molecular-weight polyethylene as a material property was set at $30 \mathrm{MPa}$ in the FEA [6].

The force levels acting on the anterior and posterior surfaces of posts have not been clarified, and there are only a few reports. Based on a study reporting that an about $100 \mathrm{~N}$ force was produced by contact between the anterior surface of the post and femoral component upon taking a step forward and placing the heel on the ground, Hamai et al. reproduced and measured this contact using a pressure sensor [7]. The flexion angle was $-15^{\circ}$ to $5^{\circ}$ including overextension (knee extension exceeding $180^{\circ}$ ). Li et al. determined the force produced on the anterior surface of the post using knee joints of a robot and cadaver, and it was $252.4 \pm 173.0 \mathrm{~N}$ at $-9^{\circ}$ [8]. This value shows a possibility of producing $400 \mathrm{~N}$ or higher force on the anterior surface of the post. Akasaki et al. loaded the femoral component with $500 \mathrm{~N}$ on the posterior surface of the post using a commercial PS-type artificial knee joint and determined the pressure produced [9]. Nakayama et al. reported an influence of internal rotation of the polyethylene insert under the same conditions [10]. Based on these findings, the measurement conditions of the mechanical test and FEA were set at $-10^{\circ}$ and $120^{\circ}$ flexion, and $120^{\circ}$ flexion $+10^{\circ}$ internal rotation of the insert, and the load was set at 500 and $1000 \mathrm{~N}$. Occurrence of 1000 Nweight-bearing on the post in daily life is unlikely, but it may be necessary to consider its influence because recently some patients perform sports, such as golf and swimming, after artificial joint placement.

The maximum surface pressure loaded on the post on the mechanical experiment was consistent with the value on FEA, with a maximum error of $14.4 \%$. Accordingly, the results of FEA may have been valid. On FEA, not only the surface pressure but also the Von Mises-equivalent stress and shear strain can be determined, and these cannot actually be measured. If the results of FEA are valid, these values may be reliable. Von Mises-equivalent stress is used as a yield index of materials for strength-designing, and it was considered appropriate to be used as a criterion of post breakage, which is the objective of this study.

When $500 \mathrm{~N}$ was loaded, Von Mises-equivalent stress was lower than the defined yield stress (30 $\mathrm{MPa}$ ) in all products and under all measurement conditions, suggesting that $500 \mathrm{~N}$ weight-bearing on the post does not cause plastic deformation. Walking, using the stairs, and standing up from a sitting position are unlikely to produce a backward force exceeding $500 \mathrm{~N}$ on the knee joint, suggesting that these daily motions do not break the post [11]. Regarding the measurement conditions, relatively high Von Mises-equivalent stress was produced at $-10^{\circ}$ flexion, whereas it was low at $120^{\circ}$ flexion. No marked difference was noted among the three products. Therefore, the risk of breakage is higher on the anterior than posterior surface of posts, and this may support the reported finding that the cause of post breakage was 
impingement at the anterior region of the post. When $1000 \mathrm{~N}$ was loaded, Von Mises-equivalent stress exceeding the yield stress was produced at $-10^{\circ}$ flexion in all products. However, stress exceeding $30 \mathrm{MPa}$ was produced at the contact point between the post and cam, and stress produced at the root was about 10 $\mathrm{MPa}$ in all products. Assuming that plastic deformation at the contact point is acceptable to some extent, it is unlikely that $1000 \mathrm{~N}$ force loaded on the post causes breakage.

Considering the condition producing Von Mises-equivalent stress exceeding $30 \mathrm{MPa}$ at the root of a post based on this, a force $(3000 \mathrm{~N})$ three times higher than this condition was loaded on the anterior surface of the post, i.e., a large load equivalent to this may have been loaded on the post in clinical cases of post breakage. Additional analysis is necessary to demonstrate this.

When $120^{\circ}$ flexion and $120^{\circ}$ flexion $+10^{\circ}$ internal rotation were compared, differences due to the post shape were observed. Since the post and cam were flat-shaped in products A and C, internal rotation of the insert may have caused stress concentration on the edge of the post (edge loading). In product A, $120^{\circ}$ flexion $+10^{\circ}$ internal rotation also caused stress exceeding the defined yield stress of Von Mises-equivalent stress. However, Von Mises-equivalent stress was produced at the post-cam contact point and due to a compressive force, this stress was considered unlikely to break the post.

On the other hand, no stress exceeding the yield stress was produced in products B and C, suggesting that the possibility of breakage of the posterior surface of the posts is low. In product B, since the post-cam shape is curved, even though internal rotation of the insert occurred, the contact area may not have markedly decreased and the increase in stress induced by internal rotation of the insert may have decreased. In previous reports, stress production was smaller in the curve-shaped post-cam design than in the flat-shaped design, and our analysis obtained similar results. In addition, an inverse correlation $(\mathrm{r}=-0.75)$ was observed between the measured pressurized area and Von Mises-equivalent stress on analysis. Accordingly, an increase in the post-cam contact area reduces stress. It was suggested that to reduce the risk of breakage, a curved shape with high fit is important for the posterior surface of the post and cam of the femoral component, such as the post-cam in product B. Since Von Mises-equivalent stress of the post of product $\mathrm{C}$ was higher than that of product $\mathrm{B}$, no advantage of a large size, such as product $\mathrm{C}$, was confirmed. Considering that the amount of osteotomy increases as the post volume increases and joint restriction also increases after surgery, the post volumes of products $\mathrm{A}$ and $\mathrm{C}$ may be sufficient.

\section{CONCLUSION}

Von Mises-equivalent stress and shear strain produced in the post of the commercial Posterior-Stabilized-type knee prostheses were determined by performing compression test and finite element analysis. It is unlikely that a $1000 \mathrm{~N}$ force causes post breakage, but it may occur when a $3000 \mathrm{~N}$ force is loaded on the anterior surface of the post. It may be desirable that the post-cam shape is curved with high fit. When attention is paid to shear strain, the value was high when stress exceeded the yield stress (30 $\mathrm{MPa}$ ), and the value exceeded 0.1 in all products, suggesting that when strain is employed as a criterion, a shear strain value of 0.1 may be applicable. It was assumed that post breakage occurs when shear strain at the root of the post exceeds 0.1 .

\section{ACKNOWLEDGEMENTS}

This study was supported by the Kitasato University Research Grant for Young Researchers No. 2014-4008. We are grateful to Kensei Tanaka, Masaya Nakano, and Yuya Taira for their support.

\section{CONFLICTS OF INTEREST}

The authors declare no conflicts of interest regarding the publication of this paper.

\section{REFERENCES}

1. Kumar, N., Yadav, C., Raj, R. and Yadav, S. (2015) Fracture of the Polyethylene Tibial Post in a Posterior Stabi- 
lized Knee Prosthesis: A Case Report and Review of Literature. Journal of Orthopaedics, 12, 160-163. https://doi.org/10.1016/j.jor.2015.01.002

2. Lim, H.C., Bae, J.H., Hwang, J.H., Kim, S.J. and Yoon, J.Y. (2009) Fracture of a Polyethylene Tibial Post in a Scorpio Posterior-Stabilized Knee Prosthesis. Clinics in Orthopedic Surgery, 1, 118-121. https://doi.org/10.4055/cios.2009.1.2.118

3. Jung, K.A., Lee, S.C., Hwang, S.H. and Kim, S.M. (2008) Fracture of a Second-Generation Highly Cross-Linked UHMWPE Tibial Post in a Posterior-Stabilized Scorpio Knee System. Orthopedics, 31, 1137. https://doi.org/10.3928/01477447-20081101-10

4. Bal, B.S., Greenberg, D., Li, S., Mauerhan, D.R., Schultz, L. and Cherry, K. (2008) Tibial Post Failures in a Condylar Posterior Cruciate Substituting Total Knee Arthroplasty. The Journal of Arthroplasty, 23, 650-655. https://doi.org/10.1016/j.arth.2007.08.002

5. Chiu, Y.S., Chen, W.M., Huang, C.K., Chiang, C.C. and Chen, T.H. (2004) Fracture of the Polyethylene Tibial Post in a NexGen Posterior-Stabilized Knee Prosthesis. The Journal of Arthroplasty, 19, 1045-1049. https://doi.org/10.1016/j.arth.2004.04.013

6. Bartel, D.L., Rawlinson, J.J., Burstein, A.H., Ranawat, C.S. and Flynn, Jr., W.F. (1995) Stresses in Polyethylene Components of contemporary Total Knee Replacements. Clinical Orthopaedics Related Research, 317, 76-82.

7. Hamai, S., Miura, H., Matsuda, S., Shimoto, T., Higaki, H. and Iwamoto, Y. (2010) Contact Stress at the Anterior Aspect of the Tibial Post in Posterior-Stabilized Total Knee Replacement. The Journal of Bone and Joint Surgery America, 92, 1765-1773. https://doi.org/10.2106/jbjs.i.00479

8. Li, G., Papannagari, R., Most, E., Park, S.E., Johnson, T., Tanamal, L. and Rubash, H.E. (2005) Anterior Tibial Post Impingement in a Posterior Stabilized Total Knee Arthroplasty. Journal of Orthopaedic Research, 23, 536-541. https://doi.org/10.1016/j.orthres.2004.09.005

9. Akasaki, Y., Matsuda, S., Shimoto, T., Miura, H., Higaki, H. and Iwamoto, Y. (2008) Contact Stress Analysis of the Conforming Post-Cam Mechanism in Posterior-Stabilized Total Knee Arthroplasty. Journal of Arthroplasty, 23, 736-748. https://doi.org/10.1016/j.arth.2007.05.023

10. Nakayama, K., Matsuda, S., Miura, H., Higaki, H., Otsuka, K. and Iwamoto, Y. (2005) Contact Stress at the Post-Cam Mechanism in Posterior-Stabilised Total Knee Arthroplasty. The Journal of Bone and Joint Surgery British, 87-B, 483-488. https://doi.org/10.1302/0301-620x.87b4.15684

11. Nagura, T., Dyrby, C.O., Alexander, E.J. and Andriacchi, T.P. (2002) Mechanical Loads at the Knee Joint during Deep Flexion. Journal of Orthopaedic Research, 20, 881-886. https://doi.org/10.1016/s0736-0266(01)00178-4 